\title{
Peer Learning in Social Media Enhanced Learning Environment
}

\author{
http://dx.doi.org/10.3991/ijet.v7i3.2173 \\ A-M. Tervakari, K. Silius, T. Tebest, J. Marttila, M Kailanto and J. Huhtamäki \\ Tampere University of Technology, Tampere, Finland
}

\begin{abstract}
TUT Circle, a dedicated social media service for students at Tampere University of Technology (TUT), was used as a learning environment for the purpose of enhancing students' collaboration, communication and networking skills required in business and working life and for promoting peer learning in small groups. Unfortunately, active conversation was limited. The students intensively read content created by other students, but they did not actively present their opinions, arguments or comments. Another reason for the lack of real conversation was procrastination. The students seemed to need more encouragement to comment on or question the ideas of others, more support to promote intergroup interaction and more assistance with time management.
\end{abstract}

Index Terms_-Inquiry-based learning, learning analytics, peer learning, social media.

\section{INTRODUCTION}

The ability to work with others; communicate with different people; and find, utilize and distribute knowledge is increasingly required in working life where small-group problem solving has replaced top-down management. In order to succeed in their future work, students need opportunities to develop and practice their interaction, collaboration and networking skills throughout their education [1]. Opportunities to develop and practice these skills can be offered to students by encouraging them to work together and learn from each other while also learning from traditional lectures [2], [3]. When students work with peers in groups, they articulate their ideas and questions, which leads to the social processes of constructing ideas and developing solutions to problems and promotes the deeper learning of theories [1], [ 2], [3].

In the autumn of 2011, Hypermedia Laboratory at Tampere University of Technology (TUT) conducted a study of peer learning in social media enhanced web services as a part of the Finnish national project called Campus Conexus, which is being carried out from 2009 to 2013 and financed by the European Social Fund. The purpose of Campus Conexus is to strengthen the cultural practices of five Finnish universities and promote learning and teaching. The aim of the project is to determine how to engage students in university studies; for example, by enriching learning experiences and enhancing students' personal, intellectual, collegial and professional development. Three environments in which students can engage in their studies have been identified: study-related or extracurricular activities, located either on campus or off campus or in the workplace [4], [5].
According to [5], the role of the environment that supports engagement in university studies has expanded toward social media enhanced online communities. It has been noted that online communities enhance students' sense of belonging [6] and strengthen social contacts, community engagement and learning [7], [8]. Online communities often make visible the social networks that already exist in offline contexts [9] and even strengthen the ties between individuals [10]. In social media enhanced online communities, students can get to know each other and make friends outside of classes. This phenomenon has been referred to as 'glocalisation', the ability of the Internet to both expand users' social contacts and bind them more closely to the local context [11].

In earlier research related to the Campus Conexus project, it was discovered that the focus of utilizing social media enhanced web services has changed from networking to studying [5], [6], [12]. In order to design and implement social media enhanced web services such that they support learning as well as studying and teaching, the teaching experiments organized by TUT's Hypermedia Laboratory have been studied from the viewpoint of peer learning and collaboration [13], [14].

The objectives of this study were to find out 1) if the students voluntarily utilized peer learning in order to learn with and from each other without immediate teacher intervention utilizing the social media enhanced web service (TUT Circle) ${ }^{1}$, 2) how the students utilized the functionalities offered by TUT Circle, 3) the possible benefits of social media that support peer learning for students and 4) how students experienced the use of social media in small groups.

\section{ONLINE PEER LEARNING}

In all courses, students share useful information and learning experiences. When students encounter problems, they often seek help from other students rather than from the teacher. Learning from peers usually occurs informally without teacher involvement, and it particularly benefits the students who are effective learners. Formalizing peer learning by supporting students in finding opportunities for peer learning can help students to learn more effectively [1]. It is, nevertheless, important to understand that peer learning is not a single pedagogical method or approach. According to [1], [3]; peer learning includes a selection of learning activities that are mutually beneficial and involve the sharing of knowledge, ideas and experiences among participants. These participants are students who are in similar situations (i.e. none of them plays the role of 'teacher' or 'expert' in such situations).

1 http://www.tut.fi/piiri 
Peer learning can occur on a one-to-one basis, when one student collaborates, communicates and shares knowledge with a peer. Obviously, group work offers more opportunities for peer learning. In groups, students encourage and motivate each other to ask questions, explain their opinions, construct arguments, elaborate and reflect on their knowledge and thereby improve their learning [1], [2], [3]. However, it is not clear that all students benefit from group work. Some peer groups experience problems with participation, leadership, understanding and encouragement, which can lead to the devaluation of collaboration and even learning [1], [2], [15].

The learning of individual students or groups can be improved by promoting peer interaction and collaboration. The likelihood that all group members will learn the subject matter will increase when the students are encouraged to participate actively; for example, by building involvement in group discussion. Active participation is positively related to student success in online courses [15], [16].

In addition to participation, effective collaborative learning interactions also require conversation skills, social grounding, promotive interaction and group processing. For example, the quality of communication in the context of group discussion depends on students' conversation skills. In the learning context, this means knowing when to ask for help or advice; provide information, advice, feedback or reinforcement; support group cohesion or peer involvement; offer reasons for comments or suggestions; and so on. Students also need social grounding skills (i.e. the ability to switch roles between dialogue segments and take conversational turns to establish and maintain a shared understanding while ensuring their own understanding of the knowledge presented by others). To promote interaction, students can be asked to play a certain role (e.g. questioner, advisor, negotiator or listener) when contributing to assignments, as this supports students in developing their social grounding skills at the same time. Groups need to reflect on their performance and discuss their progress to decide on how to continue. This self-evaluation helps groups to improve their behaviors and collaborations. In order to succeed, the students in the group need to work toward shared goals and understand that each individual can achieve his/her goal only if the group members achieve their goals [2].

Peer learning can benefit from online learning in many ways. Unlike traditional lectures or other conventional face-to-face learning sessions, web-based learning environments facilitate communication and collaboration within the student community by supporting information sharing and distribution of materials, providing collaborative learning tools and offering storage of large amounts of information [1], [2].

However, online learning requires a high level of motivation and good time management skills. Participation is critical to the success or failure of online learning. Active participation is clearly important for achieving better learning results, but passive participation could also be a good indicator of performance. Students who read the content and messages produced by other students can learn through passive participation (i.e. through observation). Lack of time and procrastination (i.e. the tendency to postpone important tasks) are the main reasons why students fail or drop out of online courses. Procrastination is common among university students, and it has been related to poor academic performance. Frequent procrastinators participate less and later during the learning process, and because of this, they communicate less with their peers, which has a negative impact on their performance. However, it has been assumed that frequent procrastinators are not a homogenous group of students. Some of the students seem to be 'active' procrastinators who prefer to work under pressure and make conscious decisions to procrastinate, whereas some students seem to be 'passive' procrastinators who fail to complete their tasks on time because of their indecision [15], [16].

\section{TUT CIRCLE}

During the teaching experiment under study, TUT Circle, a social media enhanced web service, was used as a learning environment. TUT Circle is built on Drupal ${ }^{2}$, a content management framework, and it was developed by the Hypermedia Laboratory at TUT. TUT Circle was introduced in 2008 with an idea to support students, especially in their mathematics studies.

Currently, TUT Circle contains all the basic functionalities of a modern social media web service, including the possibility to publish several different types of content, e.g. wiki pages, blog posts, news items, and events. The main feature of TUT Circle is its ability to support grouping. TUT Circle promotes the networking, collaboration, and communications of small groups by allowing users to form friendships with each other, send private messages, chat, create, contribute, and comment on content, exchange opinions, and share resources within and between the groups. All the content created by the users is shared through groups. When the users submit the content, they select the groups with which the content is affiliated. The users can also control the visibility of their information and control access to the information (i.e. allow access only to members of a certain group or to all users within TUT Circle).

TUT Circle also provides a good environment for applying and further developing methods of advanced data collection, analysis and representation methods i.e. learning analytics. We define "learning analytics" as 'a process or activity in which data on teaching and learning environments is systematically gathered, processed, analysed, and evaluated to support decision making, and to gain insights on teaching and learning' [17]. When compared to third-party social media platforms, a platform like TUT Circle maintained by its developers enables collection of rich data as well as the development of new features on the basis of the findings. Many of the features in TUT Circle are developed by integrating and tailoring existing Drupal modules. However, development related to learning analytics has, for now, been done by implementing tailored scripts and batch processes for exporting data directly from TUT Circle database for further analysis [17].

In addition to the teaching experiment reported in this paper, several different experiments have been conducted in TUT Circle. These include other teaching experiments and experiments with various stakeholders [5], [6], [12], [13], [14].

\section{${ }^{2}$ http://drupal.org}


PAPER

\section{TEACHING EXPERIMENT}

For the teaching experiment, TUT's Hypermedia Laboratory organized an online course named Usefulness of Web-Based Services, in which 35 students participated. During the course, TUT Circle was used as a learning environment in order to promote students' networking, collaboration and communications in small groups within the student community.

The students were offered online learning material for self-study. The material presented the basic theories on evaluation of usability, accessibility, usefulness, informational quality and user experience as well as evaluation methods, several practical tools and guidance on evaluation. In order to activate students' thinking, they were required to contribute weekly assignments by writing at least one message on a discussion forum related to a theme given by the teacher (except the first assignment, when two messages were required).

The students were asked to choose their role for the activity to overcome communication difficulties. When students wrote their answers, they had to choose if they wanted to comment on, argue or present an opinion. Through comments, students were advised to ask questions, give additional information or present a new viewpoint. In an argument, the students were required to state their conception clearly (supported by expert opinions and facts) and construct arguments that considered the issues they had studied from the learning material. When presenting opinions, the students were asked to write their answers based on their own experiences. There were nine weekly assignments altogether. The students were asked to write at least one message per assignment, but they were free to write as many messages as they wanted. In five of the assignments, the students were motivated (by extra points to be added to their final scores) to write additional messages voluntarily in order to promote information sharing and active participation.

In addition to the weekly assignments, the students were required to carry out a group-work project with the aim of evaluating the usefulness of a web-based service in order to pass the course. Thirty-five students formed nine groups and worked together until their projects were graded. Every group member received the same project grade, which was worth half of the final grade. Contributions to the weekly assignments were worth the other half of the final grade. Students also had the opportunity to earn half of one grade value to be added to their final grade by writing additional messages for five of the weekly assignments.

The teaching method of the course was based on the idea of inquiry-based learning. The students were not given any prescribed target or result that they had to achieve. Instead, the students had to discover the result of the project, and the teacher's role was to guide and provide access to theoretical information. In the groups, the students had to self-organize, establish their goals, communicate, collaborate and coordinate their purpose to solve problems and to integrate individual efforts to produce collective outcomes. Groups were offered the opportunity to receive additional guidance by inviting the teachers to join their small group. Special events were also organized to support groups in self-evaluating their progress and discussing how to proceed.
A few weeks into the course, the groups presented their plans for the evaluation of a web-based service in a faceto-face meeting with the teacher who gave them guidance on how to improve their work. The groups also published their plans in TUT Circle to obtain comments from other students. A similar arrangement was used at the end of the course when the groups presented their evaluation results and gave their suggestions on how to improve the quality of the evaluated web-based service. After that, the groups had time to improve their work before they returned their final projects to the teacher for grading.

\section{DATA COLLECTION AND ANALYSIS}

The use of web-based learning environments provides an opportunity to collect rich data on students' actions throughout courses. However, simple participation statistics may be a poor indicator of student interaction and collaboration if considered alone [2]. Data for this study were collected, in parts, from two different sources. Firstly, log data collected from TUT Circle were analyzed using sophisticated methods and visualized to verify interaction among students and content. Secondly, the students participating in the course responded to a survey. The aim of the survey was to gather information about the students' experience of utilizing TUT Circle for peer learning.

TUT Circle was used to facilitate communication and collaboration between teachers and students participating in the course. The students can be considered members of the community with the target of achieving learning goals. This community can be seen as a social network, where students are connected through information exchanged in TUT Circle. Every time the students, for example, post messages or read each other's writings, information on these actions is logged in a database. The log data include the students' activity records wherein latent ties among actors are embedded. Analysis of this collected data can provide useful information about students' learning habits (e.g. favored reading materials, ways of carrying out assignments, communication with other students using forums and private messages) [18]. In addition, the results of the analysis can tell us what has happened. To understand the students' behavior, qualitative data were collected by using a web survey on themes related to peer learning and utilization of social media in group work.

The amount of log data created by even a small community can be huge, which makes the analysis of log data challenging. Social network analysis (SNA) methods were applied in analyzing the log data for the purpose of showing the existence of latent ties based on the information exchange among the group members and between the members of different groups within the student community.

Visualization of a social network effectively describes its structure and simplifies the monitoring of the activities of individuals or groups. SNA and graph theory-based models and metrics can be used to measure and visualize network-like phenomena [19]. Visualization of social configurations 'allows investigators to gain new insights into the patterning of social connections, and it helps investigators to communicate their results to others' [20]. 


\section{RESULTS}

\section{A. SNA and visualizations of network activity}

The log data collected from TUT Circle, which consisted of user interactions carried out in TUT Circle, was used as a source of research data. This data was gathered using tailored data-collection methods and modeled into a network that represents the interactions between students and content. SNA methods were used to model and analyze the collected log data (Fig. 1).

From the network seen in Fig. 1, it is evident that students actively read content produced by others but that some students seem to have been more active than others. The most popular content nodes were the forum posts in which students contributed their weekly exercises. Teachers can validate the existence of passive participation and peer learning from this kind of analysis.

Students' contributions to the course were visualized with Gource ${ }^{3}$, a software version control visualization tool developed for creating animations on the evolution of collaboratively created artifacts. In Fig. 2 and Fig. 3 red nodes represent forum discussions, blue nodes represent blog posts, yellow nodes represent wiki pages, pink nodes represent events and green nodes represent news items. Comments to these types of content are represented as a tree structure under the node to which they are related.

The actual visualization created with Gource is a dynamic time-driven video. To convey insights on the dynamics, two snapshots from interesting time points are presented here: The situation on Friday is seen in Fig. 2.

It shows that some students had already returned their exercise work to the forum post (seen in the bottom-right corner) but that most of the students returned the exercise just before the deadline on Monday (seen in the activity in Fig. 3). At this point, the first assignment had already been returned to the forum post (seen in the bottom-left corners of Fig. 2 and Fig. 3). The other content seen includes, for example, various course information and study-group presentations.

The visualization shows that students presented with burst-like behavior when returning their weekly assignments. Although students had time to return their assignments during the week, most of the students made the return just before the deadline on Monday. This behavior was observed during the entire course for all the assignments. However, as seen in the questionnaire, this does not necessarily mean that the students are writing their assignments at the last moment but that they are submitting them at the last minute.

From the Gource-based visualization, it is also evident that voluntary discussion in the forum (seen in Fig. 2 and Fig. 3 as branches that form from the forum topic seen in the middle) was only seen in the first week's assignment, when two messages were required. The lack of voluntary contribution was seen throughout the rest of the course.

According to the results of SNA and visualizations of network activity, the students seemed to read the messages of others on the course discussion forum and groups' public reports quite intensively. However, only a few students voluntarily commented on content created by other students. Student interaction on the course level seemed to happen in bursts. The interaction started slowly,

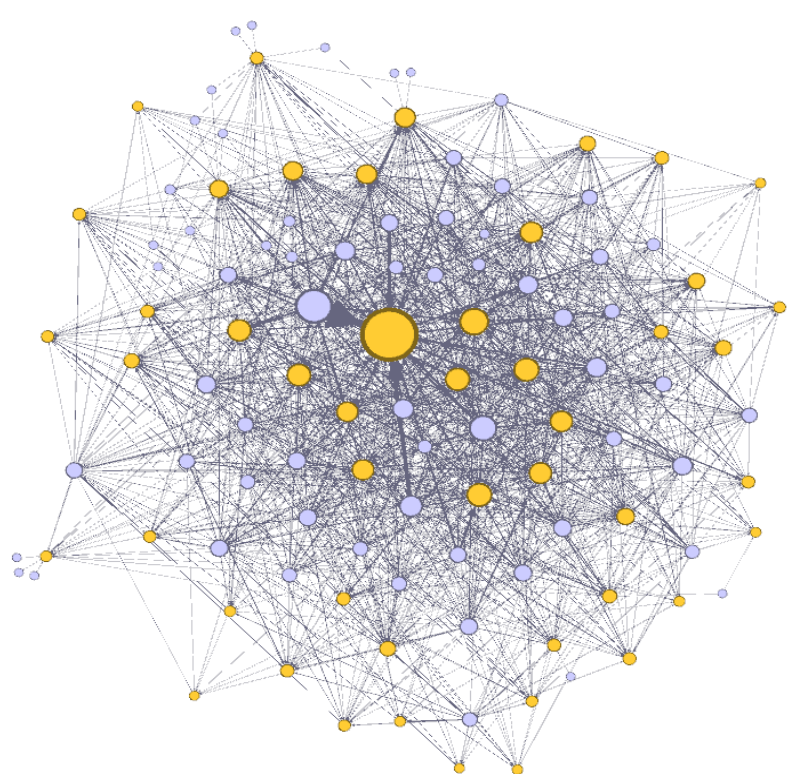

Figure 1. (Social) network of users and content on the course. Orange nodes in the figure represent content, and blue nodes represent users. The strength of the connection is relative to the number of interactions (readings) between the user and content. The large blue nodes represent more active students, and the large orange nodes represent more popular content.

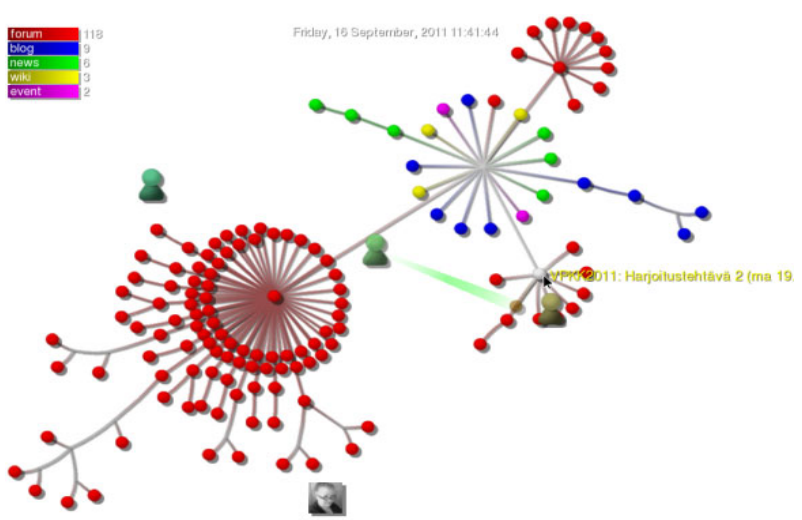

Figure 2. The situation on Friday, September 15. Some students had returned their exercise work to the forum post (seen in the bottom-right corner).

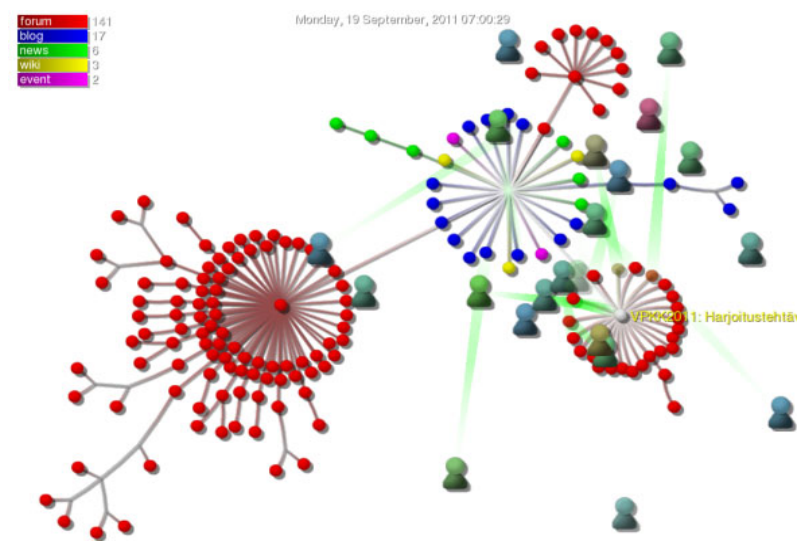

Figure 3. The situation on early Monday morning. Most of the students returned their exercise work at the last moment. All the avatars seemed to gather around the forum post where the return was made. 
and most of the network activity happened around the assignment deadlines. The interaction between the groups was quite moderate, mainly because the students seemed to strictly control the visibility of the content of their groups. Out-group students or teachers were only able to read the content required to be visible to other students of the course.

\section{B. Survey of the students' experiences of peer learning in social media}

The web survey was carried out in the autumn of 2011 when 35 students answered the survey as a part of their course assignment. The students were asked to rate their agreement or disagreement with the 14 survey statements on a 5-point Likert-type scale. The survey aimed to determine if the students found peer learning activities useful for their learning and how they experienced those activities. There were also three open-ended questions in the survey. The first one aimed to elicit answers about students' roles in virtual and ordinary groups. Two other questions aimed to determine students' perceptions of the reasons for the procrastination and its impact on learning.

Results from the analysis of the survey data are presented in Table 1 . The qualitative data from openended questions were analyzed using content analysis, a method used to examine the meanings, themes and patterns that were manifest or latent in the students' answers and to identify similarities and differences among answers. To ensure the validity of the analysis, triangulation was used. In other words, the researchers read through the material, coded the data and developed classifications separately. Afterwards, they compared the classifications and formalized the results.

According to the results of the analysis, when one-third of the students thought that sharing, presenting and producing information was easy in TUT Circle, roughly half of them seemed to consider these tasks difficult. Half of respondents (54\%) disagreed or strongly disagreed that it was easy to share content, web links and other resources in TUT Circle. Forty per cent of respondents disagreed or strongly disagreed that it was easy to present their ideas, opinions and questions in TUT Circle. Half of respondents (52\%) also disagreed or strongly disagreed that it was easy to comment on the messages or work of other students in TUT Circle. (See statements 1, 3 and 5 in Table 1.)

The students seemed to have different opinions concerning whether the sharing, presenting and producing of information in TUT Circle was useful for their learning. One-third of respondents (34\%) agreed or strongly agreed that sharing content, web links and other resources in TUT Circle was useful for their learning. Thirty-seven per cent of respondents agreed or strongly agreed that commenting on the work of other students in TUT Circle was useful for their learning, and only $26 \%$ of them agreed or strongly agreed that presenting their own ideas, opinions and questions was useful for their learning. (See statements 2, 4 and 6 in Table 1.)

The students still thought that receiving comments on their own messages and work was a positive experience. Fifty-seven per cent of respondents agreed or strongly agreed that the comments on their own messages and work received in TUT Circle were useful for their learning, and $63 \%$ of them agreed or strongly agreed that reading other students' messages and work was useful for learning. Forty-one per cent of respondents agreed or
TABLE I.

THE DIVISION AMONG THE STUDENTS ACCORDING TO THEIR LEVEL OF AGREEMENT WITH STATEMENTS. $(\mathrm{N}=35)$

\begin{tabular}{|c|c|c|c|c|c|}
\hline Statements & A & B & $\mathrm{C}$ & Av. & St.dv. \\
\hline $\begin{array}{l}\text { 1. It was easy for me to share } \\
\text { content, web links and other re- } \\
\text { sources in TUT Circle. }\end{array}$ & 54 & 17 & 29 & 2.63 & 1.03 \\
\hline $\begin{array}{l}\text { 2. Sharing content, links and } \\
\text { other resources in TUT Circle } \\
\text { was useful for my learning. }\end{array}$ & 34 & 31 & 34 & 3.00 & 0.94 \\
\hline $\begin{array}{l}\text { 3. It was easy for me to present } \\
\text { my ideas, opinions and ques- } \\
\text { tions related to subject matter in } \\
\text { TUT Circle. }\end{array}$ & 40 & 26 & 34 & 2.86 & 1.09 \\
\hline $\begin{array}{l}\text { 4. Presenting my ideas, opin- } \\
\text { ions and questions related to } \\
\text { subject matter in TUT Circle } \\
\text { was useful for my learning. }\end{array}$ & 40 & 34 & 26 & 2.77 & 0.94 \\
\hline $\begin{array}{l}\text { 5. It was easy for me to com- } \\
\text { ment on the messages and work } \\
\text { of other students in TUT Circle. }\end{array}$ & 52 & 15 & 33 & 2.64 & 1.29 \\
\hline $\begin{array}{l}\text { 6. Commenting on the mes- } \\
\text { sages and work of other stu- } \\
\text { dents in TUT Circle was useful } \\
\text { for my learning. }\end{array}$ & 29 & 34 & 37 & 3.09 & 0.82 \\
\hline $\begin{array}{l}\text { 7. Receiving comments on my } \\
\text { own messages and work in } \\
\text { TUT Circle was a positive ex- } \\
\text { perience. }\end{array}$ & 11 & 37 & 51 & 3.49 & 0.82 \\
\hline $\begin{array}{l}\text { 8. The comments on my own } \\
\text { messages and work received in } \\
\text { TUT Circle were useful for my } \\
\text { learning. }\end{array}$ & 11 & 31 & 57 & 3.51 & 0.89 \\
\hline $\begin{array}{l}\text { 9. Reading the messages and } \\
\text { work written by other students } \\
\text { was useful for my learning. }\end{array}$ & 14 & 23 & 63 & 3.60 & 1.06 \\
\hline $\begin{array}{l}\text { 10. Content, links and other re- } \\
\text { sources shared by other stu- } \\
\text { dents were useful for my learn- } \\
\text { ing. }\end{array}$ & 21 & 28 & 14 & 3.21 & 0.98 \\
\hline $\begin{array}{l}\text { 11. The functionalities and fea- } \\
\text { tures of TUT Circle support in- } \\
\text { teraction among students. }\end{array}$ & 63 & 17 & 20 & 2.31 & 1.08 \\
\hline $\begin{array}{l}\text { 12. The functionalities and fea- } \\
\text { tures of TUT Circle support in- } \\
\text { teraction between students and } \\
\text { teachers. }\end{array}$ & 46 & 26 & 29 & 2.74 & 1.15 \\
\hline $\begin{array}{l}\text { 13. The functionalities and fea- } \\
\text { tures of TUT Circle support } \\
\text { group work. }\end{array}$ & 67 & 15 & 18 & 2.24 & 1.15 \\
\hline $\begin{array}{l}\text { 14. My role in virtual small } \\
\text { group was similar to my role in } \\
\text { a small group having face-to- } \\
\text { face meetings. }\end{array}$ & 17 & 26 & 57 & 3.49 & 1.07 \\
\hline
\end{tabular}

$\mathrm{A}=$ disagreed or strongly disagreed, $\mathrm{B}=$ neutral, $\mathrm{C}=$ agreed or strongly agreed

strongly agreed that contents, links and other resources shared by other students were useful for their learning. (See statements 7-10 in Table 1.)

Roughly half of the students found that the functionalities and features of TUT Circle did not support peer learning. Sixty-three per cent of respondents disagreed or strongly disagreed that the functionalities and features of TUT Circle support interaction among students, almost half of respondents (46\%) disagreed or strongly disagreed that they support interaction between students and teachers and $67 \%$ of the respondents disagreed or strongly disagreed that they support group work. (See statements 11-13 in Table 1.)

It was also interesting to see if the students perceived their roles in the virtual groups as different from those in 
face-to-face groups. (See statement 14 in Table 1.) Fiftyseven per cent of respondents agreed or strongly agreed that their role was the same despite the form of group, and $17 \%$ disagreed or strongly disagreed with this statement. One open-ended question in the survey aimed to elicit an explanation of this. Those who disagreed or strongly disagreed pointed out that interaction on the web is more time consuming and straightforward, whereas face-to-face interaction is more sensitive to individuals' moods and reactions.

'In addition, the delayed feedback and . . . the asynchronization in the work cause trouble, and it is not possible to maintain the normal conversational role.' Respondent $14^{4}$

It has previously been identified that procrastination can be seen from both positive and negative points of view [15], and this also came out in the students' answers. First, the students were asked to indicate what they perceived as being the reason for the procrastination. Half of the respondents (17/35) mentioned being hurried, primarily due to other courses and tasks, as a reason.

'Tasks need to be returned in almost every course, so in some courses, it is a necessity to practice procrastination because of the lack of time.' -Respondent 21

Attitude (laziness, inefficiency and prioritization) and the thought that the phenomenon is natural for humans were presented in the explanations of one-third (12/35) of the respondents.

'The way of thinking: 'It can be done later.',Respondent 24

Working habits (i.e. the task is done early but left to mature before submission) were mentioned by 8 out of the 35 respondents.

'I at least leave the task to 'mature' [in case] I . . . come up with some improvements to it.'-Respondent 8

Six respondents out of 35 thought that external pressure was the motivating factor for completing the task, and it was seen as one reason for last-minute performance.

'Obligation is a good motivator.'-Respondent 28

A sense of obligation was seen as necessary for time management with other courses, but for two respondents, the fact that the task was not interesting was considered the reason for the procrastination.

'The work is returned right before the deadline if it is not an interesting task.'-Respondent 20

Two students mentioned that returns are made close to deadlines, because students are not encouraged to make early returns in any way (e.g. via bonus points).

Early return[s are] not rewarded in any way.'Respondent 5

Procrastination was seen to have a positive influence on learning by 10 out of 35 respondents, while 16 thought it has a negative influence. Six respondents perceived both positive and negative effects. In terms of positives, students mentioned that it helps with scheduling and that several deadlines divide the workload for the whole course, the pressure helps them concentrate on what is essential and it is possible to read other students' answers and deepen one's own thinking. In terms of negatives, students mentioned feelings of being hurried or pressured,

4 The responses of participants were originally in Finnish, and they have been translated into English. the fact that it is not possible to address the matter fully and the fact that the learning is only superficial.

'[It affects] how long and how deeply you focus on the task. Even [if] the task is returned [at] the last minute, it might have been processed for a long time.'-Respondent 32

\section{DISCUSSION AND CONCLUSIONS}

Hypermedia Laboratory at TUT organized a teaching experiment on peer learning in the autumn of 2011 in order to offer students opportunities to work together, learn from each other and develop and practice their interaction, collaboration and networking skills. TUT Circle, a social media web service, was used as a learning environment to facilitate communication and collaboration within the student community as well as storage of information and materials.

In order to promote peer learning and activate students' thinking, the students were required to answer assignment questions weekly and present their opinions, arguments or comments on a course discussion forum. Afterwards, peer learning was validated with a user survey and visualizations based on the analysis of log data.

According to the survey results, the functionalities in TUT Circle allowed learners to collaborate and interact by means of peer learning. However, half of the respondents thought that TUT Circle did not support interaction or group work. The students had these contrary opinions, perhaps because the new TUT Circle graphical user interface was implemented midway through the course. Though the new interface is more usable than the old one, the students who were used to using the old interface might have found the new interface awkward to use.

From the SNA and the visualization of the log data, it is evident that most of the students only sent the required messages, and only a few students sent additional comments voluntarily, even though they were motivated (via bonus points) to send more messages. There could be several explanation for this. At first, half of the students found that sharing, presenting and producing information was not easy in TUT Circle, as shown in the survey results. The graphical interface change could have caused some difficulties for the students. Secondly, procrastination also challenged students. According to the students, it was difficult to discuss or comment, because the other students wrote their answers just before the assignment deadline, making meaningful conversation quite impossible. Thirdly, only one third or even fewer of the students found the sharing or contributing of content to be useful for their learning, as results of the survey showed.

Active participation is undoubtedly an important aspect of peer learning, but passive participation can also promote learning [15]. As the results of SNA and visualizations showed, the students seemed to read the messages of others on the course discussion forum and groups' public reports quite intensively. According to the survey results, over half of the students found contributions made by the other students useful for their learning.

According to the results, procrastination also seemed to hinder peer learning. Though the students always had one week's time to answer the assignment questions, most of them sent their answers late, just before the deadline. Thus, some students felt they did not have time to discuss 
or develop a shared understanding of the subject matter. Related to procrastination, students reported feeling hurried, pressured and a sense of superficial learning, which also had a negative impact.

Some of the students who participated in the course seemed to be active procrastinators, who made a conscious decision to procrastinate. Some of them mentioned that they had written their answers earlier but wanted to read other students' answers before sending their own to improve their assignments. Unlike passive procrastinators, who had problems completing their tasks on time, the active procrastinators usually did not have problems with motivation. When asked why they procrastinated, some of the passive procrastinators mentioned that they were not interested in the subject matter or that they had problems with their attitude toward learning (i.e. laziness).

The results of this study are not generalizable beyond the immediate case in the conventional sense from the study sample to the entire population. Because of the small sample size, only partial generalizations to similar populations are possible. Even so, different respondents could behave and respond differently.

The aim of this study was to examine the phenomenon of peer learning from different perspectives in order to enhance teachers' understanding of the challenges of peer learning and potentially produce valuable information for both teachers and students. Further research is still needed to better understand how to promote active participation in online learning in general, how to encourage passive procrastinators to participate more actively and the kind of interventions that could change the current 'deadline culture' towards one of on-going participation.

This study pave the way for the future use of learning analytics on TUT Circle. Learning analytics provides possibilities to verify student interaction and collaboration activities, show latent ties among students and contents, and observe the evolution of student participation. For teachers, these kinds of tools can provide valuable insight into student activity and participation, and thus help evaluate the quality of a course's instructional design. The tools may also help students to monitor and evaluate their performance processes and learning outcomes thus increasing their motivation from added transparency, and make strategic adjustments to improve their performance [17]. In the future, we aim to take steps to fully cover the process of learning analytics by developing metrics and visual tools for students and teachers to use in TUT Circle.

\section{REFERENCES}

[1] D. Boud, and A. Lee, "Peer learning as pedagogic discourse for research education," Studies in Higher Educ., vol. 30, no. 5, pp. 501 - 516, 2005. http://dx.doi.org/10.1080/03075070500249138

[2] A. Soller, "Supporting social interaction in an intelligent collaborative learning system," Int. J. of Artificial Intell. in Educ., vol. 12, no. 1, pp. 40 - 62, 2001.

[3] D. Boud, R. Cohen, and J. Sampson, "Peer learning and assessment," Assessment and Evaluation in Higher Educ., vol. 24, no. 4, pp. 413-426, 1999. http://dx.doi.org/10.1080/02602939 $\underline{90240405}$

[4] K. L. Krause, "Social involvement and commuter students: The first-year student voice,” J. First Year Experience and Students in Transition, vol. 19, no. 1, pp. 27-45, 2007.

[5] J. Annala, M. Mäkinen, P. Svärd, K. Silius and T. Miilumäki, "Online community environment promoting engagement in higher education,” SLS J. - Stud. for the Learning Soc., vol. 2, pp. 75-86, 2012. http://dx.doi.org/10.2478/v10240-012-0007-0
[6] K. Silius et al., "Students' motivations for social media enhanced studying and learning," Knowledge Manage. \& E-Learning: An Int. J. (KM\&EL), vol. 2, no. 1, pp. 51-67, March 2010.

[7] A. Kavanaugh, J. M. Carroll, M. B. Rosson, T. T. Zin and D.D.Reese, "Community networks: where offline communities meet online," J. of Computer-Mediated Communication, vol. 10, no. 4, article3, 2005.

[8] S. Minocha, "A case study-based investigation of students' experiences with social software tools," New Review of Hypermedia and Multimedia, vol. 15, no. 3, pp. 245-265, 2009. http://dx.doi.org/10.1080/13614560903494320

[9] d. boyd and N. Ellison, "Social network sites: definition, history, and scholarship," J. of Computer-Mediated Communication, Vol. 13, No. 1, article 11, 2007.

[10] J. Donath and d. boyd, "Public displays of connection," BT Technology J., vol. 22, no. 4, pp. 71-82, 2004. http://dx.doi.org/10.1023/B:BTTJ.0000047585.06264.cc

[11] B. Wellman, "Designing the Internet for a networked society: little boxes, glocalization, and networked individualism," Commun. of the ACM, vol. 45, no. 5, pp. 91-96, 2002. http://dx.doi.org/ 10.1145/506218.506221

[12] K. Silius, M. Kailanto, and A-M. Tervakari, "Evaluating the quality of social media in an educational context," Int. J. of Emerging Technologies in Learning, vol. 6, no. 3, pp. 21-27, 2011. http://online-journals.org/i-jet/article/view/1655

[13] K. Silius et al., "Programming of hypermedia - course implementation in social media," in Proc. 2011 2nd Int. Congr. on Comput. Applicat. and Computational Sci. Advances in Intelligent and Soft Computing, vol. 144/2012, pp. 369-376, 2012. doi: http://dx.doi.org/10.1007/978-3-642-28314-7 50

[14] K. Silius et al., "Developing an online publication - collaborating among students in different disciplines," in Proc. 2011 2nd Int. Congr. on Comput. Applicat. and Computational Sci. Advances in Intelligent and Soft Computing, vol . 144/2012, pp. 361-367, 2012. doi: http://dx.doi.org/10.1007/978-3-642-28314-7_49

[15] N. Michinov, S. Brunot, O. Le Bohec, J. Juhel and M. Delaval, "Procrastination, participation, and performance in online learning environments,” Comput. \& Educ., vol. 56, no. 1, pp. 243-252, 2011. http://dx.doi.org/10.1016/j.compedu.2010.07.025

[16] P. Steel, "The nature of procrastination: a meta-analytic and theoretical review of quintessential self-regulatory failure," Psychological Bulletin,. vol. 131, no. 1, pp. 65-94, 2007. http://dx.doi.org/10.1037/0033-2909.133.1.65

[17] A-M. Tervakari et al., "Developing learning analytics for TUT Circle," Open and Social Technologies for Networked Learning Conf. (OST'12) 30 July - 3 August 2012, Tallinn, Estonia, in press.

[18] P. Drázdilová, G. Obadi, K. Slaninová, J. Martinovic and V. Snásel, "Analysis and visualization of relations in eLearning," in Computational Social Network Anal.: Trends, Tools and Research Advances, A. Abraham, A-E. Hassanien and V. Snásel, Eds. London: Springer-Verlag London, 2010. doi: http://dx.doi.org/10.1007/978-1-84882-229-0_11.

[19] S. Wasserman and K. Faust, Social Network Anal. Methods and Applicat.. New York: Cambridge University Press, 1994.

[20] L.C. Freeman, "Methods for social network visualization," in Encyclopedia of Complexity and Syst. Sci., R.A. Meyers, Eds. Berlin: Springer, 2009.

\section{AUTHORS}

A-M. Tervakari is with Hypermedia Laboratory, Department of Mathematics, Tampere University of Technology, Tampere, Finland (anne.tervakari@tut.fi).

K. Silius is with Hypermedia Laboratory, Department of Mathematics, Tampere University of Technology, Tampere, Finland (kirsi.silius@tut.fi).

T. Tebest was with Hypermedia Laboratory, Department of Mathematics, Tampere University of Technology, Tampere, Finland. He is now with the YLE Finnish Broadcasting Company, Helsinki, Finland (teemo.tebest@gmail.com). 
PAPER

PeER Learning in Social Media EnHANCed LeARning EnVIRONMEnT

J. Marttila is with Hypermedia Laboratory, Department of Mathematics, Tampere University of Technology, Tampere, Finland (jarno.marttila@tut.fi).

M. Kailanto is with Hypermedia Laboratory, Department of Mathematics, Tampere University of Technology, Tampere, Finland (meri.kailanto@tut.fi).
J. Huhtamäki is with Hypermedia Laboratory, Department of Mathematics, Tampere University of Technology, Tampere, Finland (jukka.huhtamaki@tut.fi)

This work was supported in part by European Social Fund, North Ostrobothnia Centre for Economic Development, Transport and the Environment. Received 6 July 2012. Published as resubmitted by the authors 23 July 2012. 